Gut and Liver, Vol. 11, No. 6, November 2017, pp. 771-780

\title{
Extrahepatic Manifestations of Primary Biliary Cholangitis
}

\author{
Sara L Chalifoux ${ }^{1}$, Peter G Konyn ${ }^{2}$, Gina Choi $^{2,3}$, and Sammy Saab ${ }^{2,3}$ \\ ${ }^{1}$ Department of Medicine, Olive View-UCLA Medical Center, Sylmar, Departments of ${ }^{2}$ Medicine and ${ }^{3}$ Surgery, University of California, Los \\ Angeles, CA, USA
}

Primary biliary cholangitis (PBC) is an autoimmune liver disease characterized by progressive destruction of the intrahepatic bile ducts, leading to cholestasis. PBC is known to have both hepatic and extrahepatic manifestations. Extrahepatic manifestations are seen in up to $73 \%$ of patients with PBC, with the most common being Sjogren's syndrome, thyroid dysfunction and systemic sclerosis. It is thought that patients with PBC are at increased risk of developing these extrahepatic manifestations, almost all of which are autoimmune, because patients with autoimmune disease are at higher risk of developing another autoimmune condition. Due to the high prevalence of extrahepatic diseases in patients with $\mathrm{PBC}$, it is important to complete a thorough medical history at the time of diagnosis. Prompt recognition of extrahepatic disease can lead to improved patient outcomes and quality of life. The following review summarizes the most common extrahepatic conditions associated with PBC. (Gut Liver 2017;11:771-780)

Key Words: Primary biliary cholangitis; Liver diseases

\section{INTRODUCTION}

Primary biliary cholangitis (PBC) is an autoimmune liver disease characterized by progressive destruction of the intrahepatic bile ducts leading to cholestasis. This leads to fibrosis, which can lead to liver cirrhosis and failure. Data from the United Network for Organ Sharing shows that since ursodeoxycholic acid (UDCA) was Food and Drug Adminstration approved to treat PBC in 1997, the absolute number of liver transplantations performed for PBC decreased steadily by a mean of 5.4 cases per year, while the absolute number of liver transplantation increased by a mean of 249 cases per year between 1995 and 2006. ${ }^{1}$ It has been shown that initiating UDCA in early stages of disease improves transplant-free survival and that overall survival is similar to the general population. ${ }^{2}$

The diagnosis of PBC can be established when two of the following three criteria are met: (1) biochemical evidence of cholestasis based mainly on alkaline phosphatase elevation; (2) presence of antimitochondrial antibody; and (3) histologic evidence of nonsuppurative destructive cholangitis and destruction of interlobular ducts. ${ }^{3}$ Antimitochondrial antibody is a highly disease-specific autoantibody found in 90\% to 95\% of patients with $\mathrm{PBC}$ and in less than $1 \%$ of controls. ${ }^{4} \mathrm{PBC}$, similar to other autoimmune diseases has a female predominance, with a female-to-male ratio of 10 to $1 .^{3,5}$ Most patients are diagnosed between 40 and 60 years of age. ${ }^{4}$ A systematic review of population-based epidemiological studies reported that PBC incidence rates range from 0.9 to 5.8 per 100,000 inhabitants/year and prevalence rates range from 1.9 to 40.2 per 100,000 inhabitants/year. ${ }^{6}$ Given the high concordance rate among monozygotic twins and high level of PBC aggregates in families, there appears to be a genetic predisposition towards this disease. ${ }^{7,8}$

Fatigue is the most common clinical manifestation of PBC. It is present in up to $80 \%$ of patients and fluctuates independently of disease activity or stage. ${ }^{9}$ Interestingly, it is not alleviated by UDCA, and has even been found to persist after liver transplantation. ${ }^{10}$ Although the etiology of fatigue present in PBC is not entirely clear, one theory is that cholestasis causes accumulation of substances toxic to the brain which can lead to autonomic dysfunction, sleep disturbance, impaired concentration and memory problems. ${ }^{11,12}$ Pruritus is the second most common symptom in PBC and affects $40 \%$ to $80 \%$ of patients. ${ }^{11}$ Severity of symptoms can vary and fluctuate, and are not related to disease stage or activity. ${ }^{13}$ Hyperlipidemia affects around 75\% to $80 \%$ of patients with $\mathrm{PBC}$ and is a result of many complex processes related to biliary cholestasis. ${ }^{14}$ Because high-density lipoprotein cholesterol is disproportionally elevated compared to low-density lipoprotein cholesterol, these patients are not at increased risk for developing coronary artery disease. ${ }^{15,16}$ There

Correspondence to: Sammy Saab

Pfleger Liver Institute, UCLA Medical Center, 200 Medical Plaza, Suite 214, Los Angeles, CA 90095, USA

Tel: +1-310-206-6705, Fax: +1-310-206-4197, E-mail: SSaab@mednet.ucla.edu

Received on July 26, 2016. Accepted on August 16, 2016. Published online March 16, 2017

pISSN 1976-2283 eISSN 2005-1212 https://doi.org/10.5009/gnl16365

@) This is an Open Access article distributed under the terms of the Creative Commons Attribution Non-Commercial License (http://creativecommons.org/licenses/by-nc/4.0) which permits unrestricted non-commercial use, distribution, and reproduction in any medium, provided the original work is properly cited. 
Table 1. Direct Cholestatic-Related Manifestations of Primary Biliary Cholangitis $^{9-18}$
Fatigue
Pruritus
Hyperlipidemia
Fat-soluble vitamin malabsorption
Metabolic bone disease

is decreased bile acid secretion in PBC, so vitamin deficiencies can be present as there is increased risk of malabsorption of fatsoluble vitamins. ${ }^{17}$ Although its pathogenesis in relation to $\mathrm{PBC}$ is not completely clear, metabolic bone disease is another common complication of PBC and osteoporosis is seen in 20\% to $44 \%$ of patients (Table 1). ${ }^{18,19}$

The aforementioned clinical manifestations are well studied and recognized. However, there are additional extrahepatic manifestations unrelated to the hepatic manifestations caused by chronic cholestasis responsible for such symptoms as fatigue, pruritus, vitamin and metabolic bone disease. These extrahepatic manifestations are likely mediated by immunological mechanisms explaining why they all appear to be autoimmunerelated. Of note, these symptoms and syndromes can present before the diagnosis of PBC and the complications related to chronic cholestasis. The following review summarizes the most common extrahepatic conditions associated with PBC including Sjogren's syndrome (SS), thyroid disease, systemic sclerosis and rheumatoid arthritis (RA).

\section{METHODS}

\section{Search strategy and identification of studies}

We searched the database PubMed for all studies on various extrahepatic diseases reported in patients with PBC. We searched PubMed from its inception until July 22, 2016. We used a combination of the keywords, "primary biliary cirrhosis," "primary biliary cholangitis," "Sjogren's syndrome," "sicca complex," "thyroid disease," "Hashimoto's disease," "grave's disease," "systemic sclerosis," "scleroderma," “crest syndrome," "rheumatoid arthritis," "systemic lupus erythematosus," and "celiac disease." Bibliographies of all identified studies were also searched for relevant articles.

\section{Inclusion and exclusion data}

We included all studies published in scientific journals that provided prevalence data for the various extrahepatic manifestations of PBC, including: SS, thyroid disease, systemic sclerosis, RA, systemic lupus erythematosus (SLE), and celiac disease. No studies were excluded based on cohort size alone in order to be as inclusive as possible. Articles not in the English language were excluded.

\section{EXTRAHEPATIC MANIFESTATIONS}

\section{Sjogren's syndrome}

SS is one of the most frequently encountered extrahepatic manifestations seen in PBC, affecting between 3.5\% and 73\% of patients (Table 2). ${ }^{20-29}$ SS is a progressive autoimmune disorder characterized by a lymphocytic infiltration of the exocrine glands. Over time, this leads to decreased exocrine secretions, with the lacrimal and salivary glands most commonly affected, manifesting as ocular and oral dryness. ${ }^{30}$ The reason that SS is one of the most common extrahepatic manifestations seen in PBC likely has to do with the fact that both diseases manifest signs of chronic autoimmune epithelitis, which can explain the destruction of both bile ducts as well as certain exocrine glands. ${ }^{13}$ SS can be classified into two groups: primary and secondary SS. Primary SS presents as an entity by itself without an underlying autoimmune condition whereas secondary SS occurs in conjunction with an underlying autoimmune condition. ${ }^{31}$ The prevalence of SS ranges from $0.2 \%$ to $3 \%$ in the general population, and, similar to other autoimmune diseases, is more frequent in women with a 9:1 female to male ratio, and presents more commonly in middle age. ${ }^{32}$

\section{1) Symptoms}

Given the decrease in exocrine secretions seen in SS, patients most commonly present with dry eyes and oral complications which often include dry mouth, difficulty tasting and swallowing, gingivitis, and dental caries. Fatigue is also another common symptom in these patients. Less common symptoms include arthralgias, vasculitis and glomerulonephritis. ${ }^{31}$ NonHodgkins lymphoma (NHL) is a well-recognized complication of SS and affects between 5\% and 10\% of SS patients. A recent study has confirmed that although the absolute risk is small, concomitant SS and PBC places patients at increased risk for NHL with standardized incidence ratios of 4.9 and 3.9, respectively. ${ }^{33-35}$

\section{2) Diagnosis and treatment}

The diagnosis of SS is based on clinical symptoms, serological markers and histology. Anticentromere antibody is positive in approximately $80 \%$ of patients, while anti-Ro/Sjogren syndrome type A antigen (SSA) and anti-La/Sjogren syndrome type B antigen (SSB) are found in approximately 60\% and 40\% of SS patients, respectively. ${ }^{36}$ Diagnosis can also be made histologically by labial salivary gland biopsy. ${ }^{30}$ The Schirmer's test is a less invasive and objective measurement of tear production and is highly sensitive for the diagnosis of SS. ${ }^{37}$ It is important for patients diagnosed with SS to be referred to rheumatology and followed closely. Treatment of SS involves control of the numerous symptoms associated with exocrine gland infiltration. For xerophthalmia, artificial tears are recommended and saliva substitutes can be used for xerostomia and dysphagia. In refrac- 
tory patients, cholinergic agonists such as pilocarpine or cevimeline can be used. ${ }^{3}$ These patients also benefit from specialized dental care to prevent complications related to decreased saliva production. ${ }^{38}$

\section{Thyroid disease}

Thyroid disorders are present in $5.6 \%$ to $23.6 \%$ of patients with PBC (Table 2). ${ }^{21,23,25,39,40}$ In the United States, hypothyroidism is found in $4.6 \%$ of patients and hyperthyroidism in 1.3\% of the population. ${ }^{41}$ The reason for the increased incidence of thyroid disorders in patients with $\mathrm{PBC}$ is unknown, although the mechanism is likely autoimmune, similar to the other extrahepatic manifestations of PBC. One hypothesis to explain this increased incidence is that there is cross-reactivity of antithyroid autoantibodies in the presence of autoreactive $\mathrm{T}$ cells or similar epithelial antigens in both the liver and the thyroid. ${ }^{42}$

There have been several studies that have investigated thyroid dysfunction in PBC, and all studies suggest an increased incidence and prevalence of thyroid dysfunction in patients with PBC compared to the general population. ${ }^{39,40,43}$ Hypothyroidism

Table 2. Prevalence of Extrahepatic Manifestations of Primary Biliary Cholangitis $\mathrm{s}^{20-29,39,40,44,45}$

\begin{tabular}{|c|c|c|c|c|}
\hline Reference & Region & No. of patients & Cohort & Prevalence, \% \\
\hline \multicolumn{5}{|c|}{ Sjogren's syndrome } \\
\hline 20 & Italy & 170 & Consecutive patients with PBC evaluated at the University of Milan & 3.5 \\
\hline 21 & United States & 1,032 & Patients with PBC at 23 tertiary referral medical centers for liver diseases & 10 \\
\hline 22 & Japan & 874 & Patients with PBC included in a national multicenter survey & 20.8 \\
\hline 23 & United States & 67 & Patients with PBC evaluated at the Mayo Clinic in Rochester, MN & 24 \\
\hline 24 & United States & 38 & $\begin{array}{l}\text { Outpatients with PBC seen at the National Institute of Diabetes and Digestive } \\
\text { and Kidney Diseases }\end{array}$ & 47.4 \\
\hline 25 & Italy & 361 & Patients with $\mathrm{PBC}$ at a referral tertiary care center & 56.1 \\
\hline 26 & United States & 113 & $\begin{array}{l}\text { Patients with PBC participating in a therapeutic trial of D-penicillamine at } \\
\text { the Mayo Clinic }\end{array}$ & 66 \\
\hline 27 & Canada & 95 & $\begin{array}{l}\text { Patients with PBC evaluated at The Toronto Hospital either on the phone or } \\
\text { as outpatients }\end{array}$ & 68.4 \\
\hline 28 & United Kingdom & 18 & $\begin{array}{l}\text { Patients with PBC attending hospital at the London, St Bartholomew's and } \\
\text { Southampton general hospitals with less than } 10 \mathrm{~mm} \text { moistening of the } \\
\text { filter paper during Schirmer's type I and II tests together with corneal or } \\
\text { conjunctival staining with rose bengal }\end{array}$ & 72 \\
\hline 29 & Sweden & 26 & $\begin{array}{l}\text { Consecutive patients with } \mathrm{PBC} \text { who were evaluated at the University of } \\
\text { Umea with the presence of a Schirmer's test of less than } 5 \mathrm{~mm} \text { and corneal } \\
\text { staining with rose bengal and/or radiological findings of sialectasia }\end{array}$ & 73 \\
\hline \multicolumn{5}{|c|}{ Thyroid disease } \\
\hline 39 & United Kingdom & 95 & Patients with PBC at the King's College Hospital & 13.7 \\
\hline 40 & United States & 58 & Patients with PBC at New England Medical Center Hospital & 12 \\
\hline 22 & Japan & 874 & Patients with PBC included in a national multicenter survey & 5.6 \\
\hline 21 & United States & 1,032 & Patients with PBC at 23 tertiary referral medical centers for liver diseases & 9 \\
\hline 23 & United States & 67 & Patients with PBC evaluated at the Mayo Clinic in Rochester, MN & 13 \\
\hline 25 & Italy & 361 & Patients with PBC at a referral tertiary care center & 23.6 \\
\hline \multicolumn{5}{|c|}{ Systemic sclerosis } \\
\hline 22 & Japan & 874 & Patients with PBC included in a national multicenter survey & 1.4 \\
\hline 21 & United States & 1,032 & Patients with PBC at 23 tertiary referral medical centers for liver diseases & 2 \\
\hline 44 & Japan & 5,805 & $\begin{array}{l}\text { Cross-sectional study of patients with PBC registered to receive public finan- } \\
\text { cial aid from the Ministry of Health, Labour and Welfare }\end{array}$ & 2 \\
\hline 45 & United States & 558 & Patients with PBC and scleroderma seen at the Mayo Clinic & 3.9 \\
\hline 25 & Italy & 361 & Patients with $\mathrm{PBC}$ at a referral tertiary care center & 9.9 \\
\hline 20 & Italy & 170 & Patients with PBC seen consecutively at the University of Milan & 12.3 \\
\hline
\end{tabular}

PBC, primary biliary cholangitis. 
is most commonly seen in patients with $\mathrm{PBC}$ with the most common subtype being Hashimoto's thyroiditis. In one study, 9\% of patients with $\mathrm{PBC}$ were diagnosed with nonspecified thyroid disorders. ${ }^{21}$ Another study of patients with PBC noted that $20.4 \%$ of all patients had Hashimoto's thyroiditis while $3.2 \%$ had Grave's thyroiditis. ${ }^{25}$ The findings of a study looking at 67 patients with $\mathrm{PBC}$ showed that at initial evaluation, thyroid disease was detected in $13.5 \%$ of patients with $10.5 \%$ of having hypothyroidism and the remainder having hyperthyroidism. During follow-up, 31\% of patients were noted to have an abnormal thyroid-stimulating hormone (TSH), resulting in a proposed incidence of 2.9 people per year. Interestingly, this study found that patient age and severity of disease according to the Mayo Risk Score was not predictive of the development of thyroid disease. ${ }^{23}$

\section{1) Hashimoto's thyroiditis}

The most common thyroid disorder seen in PBC is Hashimoto's thyroiditis. It is also the most common autoimmune disorder and the most common cause of hypothyroidism. The incidence of Hashimoto's thyroiditis is 1 per 1,000 people per year and the prevalence is 8 to 26 per 1,000 people per year. ${ }^{46,47}$ These patients tend to present in the fifth decade of life. Women are at least eight times more likely to have the disease. It has also been shown to be more common in Caucasians and Asians compared to African-Americans. ${ }^{48}$ Diagnosis is based on clinical features, the presence of either thyroperoxidase antibody (found in 95\% of Hashimoto's thyroiditis patients) and less commonly, thyroglobulin antibody (found in 60\% to $80 \%$ of Hashimoto's thyroiditis patients), in addition to the appearance of the thyroid on ultrasound. ${ }^{48}$ The signs and symptoms are variable and can include constipation, dry, cold skin, bradycardia, oligomenorrhea, inability to concentrate, memory loss, and depression. ${ }^{48}$ Treatment is with levothyroxine.

\section{2) Grave's disease}

Hyperthyroidism associated with PBC has only been reported in a few cases and Grave's disease is the most common disorder seen in these patients. ${ }^{49}$ Grave's disease, which is the most common cause of hyperthyroidism, is seen in 20 to 30 per 100,000 people. It is an autoimmune thyroid disorder caused by stimulating antibodies to the thyrotropin receptor on thyroid follicular cells. ${ }^{50}$ It often presents between 30 and 60 years of age and diagnosis is made by clinical presentation, elevated levels of thyroxine (T4) and triiodothyronine (T3), and undetectable levels of TSH. Grave's disease can also be diagnosed by serum TSH receptor antibody levels, radioactive iodine uptake, and thyroid ultrasound. Symptoms are variable and include palpitations, tremulousness, heat intolerance, weight loss, diarrhea, tachycardia and anxiety. ${ }^{51}$ Treatment varies and includes use of antithyroid drugs to normalize thyroid hormone production, destruction of the thyroid using radioactive iodine and/or surgical removal of the thyroid.

\section{Systemic sclerosis}

Systemic sclerosis (SSc) is another extrahepatic manifestation of $\mathrm{PBC}$ with a prevalence rate ranging between 1.4\% and 12.3\% (Table 2). ${ }^{20-22,25,44,45} \mathrm{SSc}$ is a chronic, heterogeneous disorder whose pathogenesis is characterized by obliterative and proliferative microvascular involvement, activation of the immune system and increase of extracellular matrix deposition in the skin and internal organs. It is a multisystem autoimmune disease characterized by organ fibrosis that can involve the skin, lungs, gastrointestinal (GI) tract, heart or musculoskeletal system. There are two major disease subsets, defined by the degree and extent of skin involvement and include limited cutaneous SSc (1SSc) (formerly known as CREST syndrome) and diffuse cutaneous SSc (dSSc). ${ }^{52}$ Multiple studies have suggested that the ISSc subtype is more common in patients with $\mathrm{PBC}$, with one study demonstrating 93\% of patients with PBC with SSc having the 1SSc subtype. ${ }^{20,45,53,54}$ 1SSc is characterized by fibrosis of the skin limited to the hands, forearms and less commonly the face. $^{52}$ Patients with 1SSc usually have a long-standing history of Raynaud's phenomenon and low prevalence of lung involvement. ${ }^{52,55}$ On the other hand, dSSc is a progressive disorder that affects the extremities and trunk, and is characterized by a short duration of Raynaud's phenomena, involvement of multiple internal organs and unfavorable prognosis..$^{52,56-58}$

Based on multiple studies, PBC seems to be much more highly correlated with limited SSc and is rarer in $\mathrm{dSSc}^{20,45,53,54,59}$ In the general population, the incidence of SSc ranges from 2.3 to 22.8 cases per million and prevalence ranges from 50 to 400 cases per million, respectively. ${ }^{60,61}$ Similar to other autoimmune diseases, SSc is more common in women, with a female to male ratio ranging from 3-14:1. ${ }^{61}$ Anticentromere antibodies (ACA) are found in approximately $90 \%$ of 1SSc patients, although ACA titers do not appear to be associated with disease severity. ${ }^{52,62,63}$ Studies have also shown ACA to be present in 9\% to 30\% of patients with $\mathrm{PBC}{ }^{64-67}$ As the prevalence of ACA is higher than patients with $\mathrm{PBC}$ with SSc, this indicates that ACA can be present in PBC without the diagnosis of SSc.

\section{1) Symptoms}

The clinical manifestations of SSc are variable, with the majority of patients having skin thickening and varying degrees of internal organ involvement. Raynaud's phenomenon, which is cold and stress induced vasospasm of the digital arteries and cutaneous arterioles involved in body thermoregulation, is the most common initial symptom of SSc. ${ }^{68}$ After its onset, patients may be asymptomatic for years or rapidly develop other signs of disease. ${ }^{69}$ Another common finding of SSc is fatigue, which is usually seen early in the disease course. ${ }^{70,71}$ GI involvement is also seen in SSc, with esophageal dysfunction being the most common, leading to dysphagia, regurgitation and heartburn. 
Other GI complications of SSc include malabsorption, weight loss, bleeding, early satiety and fecal incontinence. ${ }^{72,73}$

Pulmonary involvement can also be present in SSc, and is a concerning finding, given that it is the leading cause of death in SSc. Approximately 50\% of patients with dSSc and 30\% of patients with 1SSc develop interstitial lung disease. ${ }^{74,75}$ Pulmonary vascular disease is more commonly seen in patients with 1SSc, with isolated pulmonary arterial hypertension present in 8\% to $12 \%$ of patients. ${ }^{76-78}$ Cardiac manifestations of SSc include pericardial effusion, myocardial inflammation, conduction abnormalities, and heart failure. ${ }^{79-82}$ In addition, there may be renal involvement in SSc. The most concerning disease presentation is scleroderma renal crisis (SRC). SRC is an example of accelerated arterial hypertension and/or rapidly progressive oliguric renal failure that is more common in patients with dSSc. Seventy-five percent of cases occur within the first 4 years of disease onset. ${ }^{83}$

\section{2) Diagnosis}

Given the complex pathology of SSc, both diagnosis and treatment can be difficult. In 2013, the American College of Rheumatology (ACR) and the European League Against Rheumatism (EULAR) developed a joint proposal for new classification criteria for SSc, shown in Table $3 .^{84}$ It is important to note that these criteria are not applicable to patients that have another disorder that can better explain their manifestations or in patients with skin thickening sparing their fingers. Patients having a total score of 9 or more are classified as having definite systemic sclerosis. ${ }^{84}$ When there is suspicion for SSc in PBC patients, these patients should be referred to a rheumatologist for evaluation.

\section{3) Treatment}

Given the heterogeneity of SSc, and the different number of organs involved, there are currently no single agent medications that treat the various manifestations of this disease. Therefore, treatment is often targeted, and even then, only a few therapies have shown modest benefits. ${ }^{85}$ Patients with Raynaud's symptoms are encouraged to avoid cold exposure and smoking with first-line pharmacotherapy being calcium channel blockers. In patients who are refractory to first line treatment, phosphodiesterase- 5 inhibitors can be given. ${ }^{86}$

Proton pump inhibitors are used in the treatment of esophagitis and gastritis, and promotility agents can be used to treat dysmotility issues. ${ }^{69}$ Methotrexate is used to treat early diffuse skin disease, and treatment can be transitioned to immunosuppressants such as mycophenalate mofetil and cyclophosphamide when there is concern for worsening skin disease and well as lung involvement. ${ }^{87-89}$ Biological agents such as Rituximab have also shown to improve and stabilize both skin scores and pulmonary function tests in patients with diffuse SSc. ${ }^{90}$

Treatments used for interstitial lung disease have only shown modest benefit. Cyclophosphamide is generally used as first line treatment in patients with SSc-interstitial lung disease. ${ }^{91}$ Mycophenolate mofetil is often used as maintenance therapy in patients who have already undergone induction with cyclophosphamide. ${ }^{92}$ Azathioprine has been used as an alternative agent to

Table 3. Diagnostic Criteria for Systemic Sclerosis ${ }^{67}$

\begin{tabular}{|c|c|c|}
\hline Item & Subitem & Score \\
\hline $\begin{array}{l}\text { Skin thickening of the fingers of both hands extending proximal } \\
\text { to the metacarpophalangeal joints }\end{array}$ & & 9 \\
\hline \multirow[t]{2}{*}{ Skin thickening of the fingers (Only count the highest score) } & Puffy fingers & 2 \\
\hline & $\begin{array}{l}\text { Sclerodactyly of the fingers } \\
\text { (distal to MCP and proximal to the PIPs) }\end{array}$ & 4 \\
\hline \multirow{3}{*}{$\begin{array}{l}\text { Fingertip lesions } \\
\text { (Only count the highest score) }\end{array}$} & Digital tip ulcers & 2 \\
\hline & & \\
\hline & Fingertip pitting scars & 3 \\
\hline Telangiectasia & & 2 \\
\hline Abnormal nailfold capillaries & & 2 \\
\hline Pulmonary arterial hypertension and/or interstitial lung disease & $\mathrm{PAH}$ & 2 \\
\hline (Maximum score is 2) & ILD & \\
\hline Raynaud's phenomenon & & 3 \\
\hline \multirow[t]{3}{*}{ Scleroderma related antibodies } & Anti-centromere & 3 \\
\hline & Anti-topoisomerase 1 & \\
\hline & Anti-RNA polymerase III & \\
\hline
\end{tabular}


cyclophosphamide as well as a maintenance regimen after cyclophosphamide induction. . $^{3,94}$

In patients with pulmonary arterial hypertension, agents such as phosphodiesterase- 5 inhibitors, endothelin receptor antagonists and prostacyclin analogues have proven efficacious in improving symptoms, delaying disease progression. They can also be used in combination, if indicated. ${ }^{95,96}$ Caution must be taken when using high-dose glucocorticoids to treat interstitial lung disease, as the use of these steroids can lead to an increased risk of SRC. ${ }^{97}$ In patients who develop SRC, ACE inhibitors have been shown to improve kidney function and decrease mortality among patients with SRC. ${ }^{98}$

\section{LESS COMMON EXTRAHEPATIC MANIFESTATIONS}

There are other, less recognized diseases that have higher prevalence among patients with PBC including RA, SLE, and celiac disease. Although several studies have pointed towards an association between PBC and RA, epidemiological data only suggests a prevalence rate between $1.8 \%$ and 5.6\%. ${ }^{20,99}$ One of the factors that has made it difficult to assess the true prevalence is the fact that most published studies appear to use different classification criteria for RA instead of the standardized ACR/EULAR criteria. SLE is another disease that has been associated with PBC. Studies documenting the incidence of SLE in PBC show a prevalence that is generally less than $2 \%$, but ranging between $0 \%$ and 3.7\%. . $^{20,25,54,100}$ One study that looked at 1,032 patients with $\mathrm{PBC}$ showed that $2.61 \%$ of these patients also had SLE, and that the incidence is higher than that in controls which was $0.48 \%{ }^{21}$ An association between $\mathrm{PBC}$ and celiac disease has also been suggested. Data from national Danish and Swedish registers have shown an association between $\mathrm{PBC}$ and celiac disease. A Welsh study reported a prevalence of $6 \%$ in Welsh patients with PBC..$^{101,102}$ In contrast, other European studies from Poland and Italy have shown no prevalence greater than that seen in the general population. ${ }^{103-105}$ Despite the high percentage of primary sclerosing cholangitis patients who also have inflammatory bowel disease, usually ulcerative colitis, an association between PBC and IBD is not widely recognized. ${ }^{106,107}$ Larger, prospective studies are needed to assess if there are statistically significant associations between PBC and these other diseases.

\section{CONCLUSIONS}

To date, there is no known pathogenic mechanism for the extrahepatic manifestations of PBC. Extrahepatic manifestations of PBC are generally autoimmune in nature and occur between $32 \%$ and $63 \%$ of patients. ${ }^{21,25,108}$ It is well known that people with one autoimmune disease are more prone to developing other autoimmune diseases. These patients are thought to have an underlying immunological dysfunction and the interplay between genetic, immunological, environmental and hormonal
Table 4. Laboratory Screening Recommendations for Extrahepatic Manifestations of Primary Biliary Cholangitis

\begin{tabular}{cl}
\hline Extrahepatic manifestation & Screening recommendation \\
\hline Sjogren's syndrome & Anti-Ro/SSA, anti-La/SSB \\
Thyroid disease & Thyroid panel \\
Systemic sclerosis & Anticentromere \\
\hline
\end{tabular}

SSA, Sjogren syndrome type A antigen; SSB, Sjogren syndrome type B antigen.

factors plays a role in the development of disease. It is also likely that the interaction between these factors accounts for the variability seen in the prevalence rates of extrahepatic manifestations. In patients with PBC, extrahepatic manifestations do not influence the incidence of end-stage liver disease complications, nor does it correlate with the onset of malignancies. Survival was also shown to be unchanged. ${ }^{25}$

Given the propensity for patients with PBC to develop extrahepatic manifestations, almost all of them being autoimmune, awareness and close screening is imperative. A summary of screening recommendations can be seen in Table 4. Upon initial diagnosis, a thorough review of systems should be obtained. It would also be prudent to conduct targeted serologic screening including a thyroid panel, anti-Ro/SSA, anti-La/SSB and anti-centromere antibody. Based on patient symptoms, more specific testing may be considered, such as Schirmer's test and pulmonary function tests. The patient care team should include practitioners in rheumatology, endocrinology, pulmonology and cardiology when indicated. Patients should follow regularly with their primary care physicians. As some of these extrahepatic manifestations can lead to diseases with a poor prognosis, vigilant screening and close follow-up will lead to prompt identification and treatment.

\section{CONFLICTS OF INTEREST}

No potential conflict of interest relevant to this article was reported.

\section{ACKNOWLEDGEMENTS}

Role in the study: study concept and design (S.C., S.S.); acquisition of data (S.C., P.K.); analysis and interpretation of data (S.C., P.K., G.C., S.S.); drafting of the manuscript (S.C., S.S.); critical revision of the manuscript for important intellectual content (G.C., S.S.); statistical analysis (not applicable); obtained funding (not applicable); administrative, technical, or material support; study supervision (G.C., S.S.).

\section{REFERENCES}

1. Lee J, Belanger A, Doucette JT, Stanca C, Friedman S, Bach N. 
Transplantation trends in primary biliary cirrhosis. Clin Gastroenterol Hepatol 2007;5:1313-1315.

2. Poupon RE, Lindor KD, Cauch-Dudek K, Dickson ER, Poupon R, Heathcote EJ. Combined analysis of randomized controlled trials of ursodeoxycholic acid in primary biliary cirrhosis. Gastroenterology 1997;113:884-890.

3. Lindor KD, Gershwin ME, Poupon R, et al. Primary biliary cirrhosis. Hepatology 2009;50:291-308.

4. Gershwin ME, Mackay IR. Primary biliary cirrhosis: paradigm or paradox for autoimmunity. Gastroenterology 1991;100:822-833.

5. Selmi C, Invernizzi P, Keeffe EB, et al. Epidemiology and pathogenesis of primary biliary cirrhosis. J Clin Gastroenterol 2004;38:264-271.

6. Boonstra K, Beuers U, Ponsioen CY. Epidemiology of primary sclerosing cholangitis and primary biliary cirrhosis: a systematic review. J Hepatol 2012;56:1181-1188.

7. Selmi C, Mayo MJ, Bach N, et al. Primary biliary cirrhosis in monozygotic and dizygotic twins: genetics, epigenetics, and environment. Gastroenterology 2004;127:485-492.

8. Bach N, Schaffner F. Familial primary biliary cirrhosis. J Hepatol 1994;20:698-701.

9. Witt-Sullivan H, Heathcote J, Cauch K, et al. The demography of primary biliary cirrhosis in Ontario, Canada. Hepatology 1990;12:98-105.

10. Carbone M, Bufton S, Monaco A, Griffiths L, Jones DE, Neuberger JM. The effect of liver transplantation on fatigue in patients with primary biliary cirrhosis: a prospective study. J Hepatol 2013;59:490-494

11. Carey EJ, Ali AH, Lindor KD. Primary biliary cirrhosis. Lancet 2015;386:1565-1575.

12. Dyson JK, Hirschfield GM, Adams DH, et al. Novel therapeutic targets in primary biliary cirrhosis. Nat Rev Gastroenterol Hepatol 2015;12:147-158.

13. Selmi C, Meroni PL, Gershwin ME. Primary biliary cirrhosis and Sjögren's syndrome: autoimmune epithelitis. J Autoimmun 2012;39:34-42.

14. Sorokin A, Brown JL, Thompson PD. Primary biliary cirrhosis, hyperlipidemia, and atherosclerotic risk: a systematic review. Atherosclerosis 2007;194:293-299.

15. Longo M, Crosignani A, Battezzati PM, et al. Hyperlipidaemic state and cardiovascular risk in primary biliary cirrhosis. Gut 2002;51:265-269.

16. Crippin JS, Lindor KD, Jorgensen R, et al. Hypercholesterolemia and atherosclerosis in primary biliary cirrhosis: what is the risk? Hepatology 1992;15:858-862.

17. Kaplan MM, Elta GH, Furie B, Sadowski JA, Russell RM. Fatsoluble vitamin nutriture in primary biliary cirrhosis. Gastroenterology 1988;95:787-792.

18. Raszeja-Wyszomirska J, Miazgowski T. Osteoporosis in primary biliary cirrhosis of the liver. Prz Gastroenterol 2014;9:82-87.

19. Guañabens N, Parés A, Ros I, et al. Severity of cholestasis and advanced histological stage but not menopausal status are the major risk factors for osteoporosis in primary biliary cirrhosis. J Hepatol 2005;42:573-577.

20. Marasini B, Gagetta M, Rossi V, Ferrari P. Rheumatic disorders and primary biliary cirrhosis: an appraisal of 170 Italian patients. Ann Rheum Dis 2001;60:1046-1049.

21. Gershwin ME, Selmi C, Worman HJ, et al. Risk factors and comorbidities in primary biliary cirrhosis: a controlled interviewbased study of 1032 patients. Hepatology 2005;42:1194-1202.

22. Inoue $\mathrm{K}$, Hirohara J, Nakano T, et al. Prediction of prognosis of primary biliary cirrhosis in Japan. Liver 1995;15:70-77.

23. Silveira MG, Mendes FD, Diehl NN, Enders FT, Lindor KD. Thyroid dysfunction in primary biliary cirrhosis, primary sclerosing cholangitis and non-alcoholic fatty liver disease. Liver Int 2009;29:1094-1100.

24. Tsianos EV, Hoofnagle JH, Fox PC, et al. Sjögren's syndrome in patients with primary biliary cirrhosis. Hepatology 1990;11:730734.

25. Floreani A, Franceschet I, Cazzagon N, et al. Extrahepatic autoimmune conditions associated with primary biliary cirrhosis. Clin Rev Allergy Immunol 2015;48:192-197.

26. Culp KS, Fleming CR, Duffy J, Baldus WP, Dickson ER. Autoimmune associations in primary biliary cirrhosis. Mayo Clin Proc 1982;57:365-370.

27. Mang FW, Michieletti P, O'Rourke K, et al. Primary biliary cirrhosis, sicca complex, and dysphagia. Dysphagia 1997;12:167-170.

28. Golding PL, Bown R, Mason AM, Taylor E. "Sicca complex" in liver disease. Br Med J 1970;4:340-342.

29. Uddenfeldt P, Danielsson A, Forssell A, Holm M, Ostberg Y. Features of Sjögren's syndrome in patients with primary biliary cirrhosis. J Intern Med 1991;230:443-448.

30. Vitali C, Bombardieri S, Jonsson R, et al. Classification criteria for Sjögren's syndrome: a revised version of the European criteria proposed by the American-European Consensus Group. Ann Rheum Dis 2002;61:554-558.

31. Patel R, Shahane A. The epidemiology of Sjögren's syndrome. Clin Epidemiol 2014;6:247-255.

32. Reksten TR, Jonsson MV. Sjögren's syndrome: an update on epidemiology and current insights on pathophysiology. Oral Maxillofac Surg Clin North Am 2014;26:1-12.

33. Voulgarelis M, Ziakas PD, Papageorgiou A, Baimpa E, Tzioufas AG, Moutsopoulos HM. Prognosis and outcome of non-Hodgkin lymphoma in primary Sjögren syndrome. Medicine (Baltimore) 2012;91:1-9.

34. Papageorgiou A, Ziogas DC, Mavragani CP, et al. Predicting the outcome of Sjogren's syndrome-associated non-Hodgkin's lymphoma patients. PLoS One 2015;10:e0116189.

35. Fallah M, Liu X, Ji J, Försti A, Sundquist K, Hemminki K. Autoimmune diseases associated with non-Hodgkin lymphoma: a nationwide cohort study. Ann Oncol 2014;25:2025-2030.

36. Shiboski SC, Shiboski CH, Criswell L, et al. American College of Rheumatology classification criteria for Sjögren's syndrome: a data-driven, expert consensus approach in the Sjögren's Interna- 
tional Collaborative Clinical Alliance cohort. Arthritis Care Res (Hoboken) 2012;64:475-487.

37. Mavragani CP, Moutsopoulos HM. Sjögren syndrome. CMAJ 2014;186:E579-E586.

38. Mavragani CP, Moutsopoulos HM. Conventional therapy of Sjogren's syndrome. Clin Rev Allergy Immunol 2007;32:284-291.

39. Crowe JP, Christensen E, Butler J, et al. Primary biliary cirrhosis: the prevalence of hypothyroidism and its relationship to thyroid autoantibodies and sicca syndrome. Gastroenterology 1980;78:1437-1441.

40. Elta GH, Sepersky RA, Goldberg MJ, Connors CM, Miller KB, Kaplan MM. Increased incidence of hypothyroidism in primary biliary cirrhosis. Dig Dis Sci 1983;28:971-975.

41. Hollowell JG, Staehling NW, Flanders WD, et al. Serum TSH, $\mathrm{T}(4)$, and thyroid antibodies in the United States population (1988 to 1994): National Health and Nutrition Examination Survey (NHANES III). J Clin Endocrinol Metab 2002;87:489-499.

42. Biró E, Szekanecz Z, Czirják L, et al. Association of systemic and thyroid autoimmune diseases. Clin Rheumatol 2006;25:240-245.

43. Huang MJ, Liaw YF. Clinical associations between thyroid and liver diseases. J Gastroenterol Hepatol 1995;10:344-350.

44. Sakauchi F, Mori M, Zeniya M, Toda G. A cross-sectional study of primary biliary cirrhosis in Japan: utilization of clinical data when patients applied to receive public financial aid. J Epidemiol 2005; 15:24-28.

45. Powell FC, Schroeter AL, Dickson ER. Primary biliary cirrhosis and the CREST syndrome: a report of 22 cases. Q J Med 1987;62:75-82.

46. Nieri S, Riccardo GG, Salvadori G, Surrenti C. Primary biliary cirrhosis and Graves' disease. J Clin Gastroenterol 1985;7:434-437.

47. Vanderpump MP, Tunbridge WM, French JM, et al. The incidence of thyroid disorders in the community: a twenty-year follow-up of the Whickham Survey. Clin Endocrinol (Oxf) 1995;43:55-68.

48. Jacobson DL, Gange SJ, Rose NR, Graham NM. Epidemiology and estimated population burden of selected autoimmune diseases in the United States. Clin Immunol Immunopathol 1997;84:223243.

49. Caturegli P, De Remigis A, Rose NR. Hashimoto thyroiditis: clinical and diagnostic criteria. Autoimmun Rev 2014;13:391-397.

50. Nyström HF, Jansson S, Berg G. Incidence rate and clinical features of hyperthyroidism in a long-term iodine sufficient area of Sweden (Gothenburg) 2003-2005. Clin Endocrinol (Oxf) 2013;78:768-776.

51. Burch HB, Cooper DS. Management of Graves disease: a review. JAMA 2015;314:2544-2554.

52. LeRoy EC, Black C, Fleischmajer R, et al. Scleroderma (systemic sclerosis): classification, subsets and pathogenesis. J Rheumatol 1988;15:202-205.

53. Sharif R, Mayes MD, Nicassio PM, et al. Determinants of work disability in patients with systemic sclerosis: a longitudinal study of the GENISOS cohort. Semin Arthritis Rheum 2011;41:38-47.

54. Buck U, Poole J, Mendelson C. Factors related to self-efficacy in persons with scleroderma. Musculoskeletal Care 2010;8:197-203.

55. Thoua NM, Bunce C, Brough G, Forbes A, Emmanuel AV, Denton CP. Assessment of gastrointestinal symptoms in patients with systemic sclerosis in a UK tertiary referral centre. Rheumatology (Oxford) 2010;49:1770-1775.

56. Roberts CG, Hummers LK, Ravich WJ, Wigley FM, Hutchins GM. A case-control study of the pathology of oesophageal disease in systemic sclerosis (scleroderma). Gut 2006;55:1697-1703.

57. Tyndall AJ, Bannert B, Vonk M, et al. Causes and risk factors for death in systemic sclerosis: a study from the EULAR Scleroderma Trials and Research (EUSTAR) database. Ann Rheum Dis 2010;69: 1809-1815.

58. Walker UA, Tyndall A, Czirják L, et al. Clinical risk assessment of organ manifestations in systemic sclerosis: a report from the EULAR Scleroderma Trials And Research group database. Ann Rheum Dis 2007;66:754-763.

59. Steen VD, Medsger TA Jr. Severe organ involvement in systemic sclerosis with diffuse scleroderma. Arthritis Rheum 2000;43:24372444.

60. Avouac J, Airò P, Meune C, et al. Prevalence of pulmonary hypertension in systemic sclerosis in European Caucasians and metaanalysis of 5 studies. J Rheumatol 2010;37:2290-2298.

61. Hachulla E, Gressin V, Guillevin L, et al. Early detection of pulmonary arterial hypertension in systemic sclerosis: a French nationwide prospective multicenter study. Arthritis Rheum 2005;52:3792-3800.

62. Avouac J, Huscher D, Furst DE, et al. Expert consensus for performing right heart catheterisation for suspected pulmonary arterial hypertension in systemic sclerosis: a Delphi consensus study with cluster analysis. Ann Rheum Dis 2014;73:191-197.

63. Allanore Y, Meune C, Vonk MC, et al. Prevalence and factors associated with left ventricular dysfunction in the EULAR Scleroderma Trial and Research group (EUSTAR) database of patients with systemic sclerosis. Ann Rheum Dis 2010;69:218-221.

64. West SG, Killian PJ, Lawless OJ. Association of myositis and myocarditis in progressive systemic sclerosis. Arthritis Rheum 1981;24:662-668.

65. Follansbee WP, Zerbe TR, Medsger TA Jr. Cardiac and skeletal muscle disease in systemic sclerosis (scleroderma): a high risk association. Am Heart J 1993;125:194-203.

66. Denton CP, Lapadula G, Mouthon L, Müller-Ladner U. Renal complications and scleroderma renal crisis. Rheumatology (Oxford) 2009;48 Suppl 3:iii32-iii35.

67. van den Hoogen F, Khanna D, Fransen J, et al. 2013 classification criteria for systemic sclerosis: an American college of rheumatology/European league against rheumatism collaborative initiative. Ann Rheum Dis 2013;72:1747-1755.

68. Kowal-Bielecka 0, Veale DJ. DMARDs in systemic sclerosis: do they exist? In: Distler 0, ed. Scleroderma-modern aspects of pathogenesis, diagnosis and therapy. Bremen: Uni-Med Verlag AG, 2009:89-95.

69. Bowling JC, Dowd PM. Raynaud's disease. Lancet 2003;361:2078- 
2080.

70. Shah AA, Wigley FM. My approach to the treatment of scleroderma. Mayo Clin Proc 2013;88:377-393.

71. Kowal-Bielecka 0, Distler 0. Use of methotrexate in patients with scleroderma and mixed connective tissue disease. Clin Exp Rheumatol 2010;28(5 Suppl 61):S160-S163.

72. Le EN, Wigley FM, Shah AA, Boin F, Hummers LK. Long-term experience of mycophenolate mofetil for treatment of diffuse $\mathrm{cu}-$ taneous systemic sclerosis. Ann Rheum Dis 2011;70:1104-1107.

73. Mendoza FA, Nagle SJ, Lee JB, Jimenez SA. A prospective observational study of mycophenolate mofetil treatment in progressive diffuse cutaneous systemic sclerosis of recent onset. J Rheumatol 2012;39:1241-1247.

74. Jordan S, Distler JH, Maurer B, et al. Effects and safety of rituximab in systemic sclerosis: an analysis from the European Scleroderma Trial and Research (EUSTAR) group. Ann Rheum Dis 2015;74:1188-1194.

75. Barnett AJ, Miller M, Littlejohn GO. The diagnosis and classification of scleroderma (systemic sclerosis). Postgrad Med J 1988;64:121-125.

76. Ferri C, Valentini G, Cozzi F, et al. Systemic sclerosis: demographic, clinical, and serologic features and survival in 1,012 Italian patients. Medicine (Baltimore) 2002;81:139-153.

77. Meyer OC, Fertig N, Lucas M, Somogyi N, Medsger TA Jr. Disease subsets, antinuclear antibody profile, and clinical features in 127 French and 247 US adult patients with systemic sclerosis. J Rheumatol 2007;34:104-109.

78. Hunzelmann N, Genth E, Krieg T, et al. Organ-specific diagnosis in patients with systemic sclerosis: Recommendations of the German Network for Systemic Sclerosis (DNSS). Z Rheumatol 2008;67:334-340

79. Assassi S, Fritzler MJ, Arnett FC, et al. Primary biliary cirrhosis (PBC), PBC autoantibodies, and hepatic parameter abnormalities in a large population of systemic sclerosis patients. J Rheumatol 2009;36:2250-2256.

80. Rigamonti C, Shand LM, Feudjo M, et al. Clinical features and prognosis of primary biliary cirrhosis associated with systemic sclerosis. Gut 2006;55:388-394.

81. Watt FE, James OF, Jones DE. Patterns of autoimmunity in primary biliary cirrhosis patients and their families: a populationbased cohort study. QJM 2004;97:397-406.

82. Le Guern V, Mahr A, Mouthon L, Jeanneret D, Carzon M, Guillevin L. Prevalence of systemic sclerosis in a French multi-ethnic county. Rheumatology (Oxford) 2004;43:1129-1137.

83. Chifflot H, Fautrel B, Sordet C, Chatelus E, Sibilia J. Incidence and prevalence of systemic sclerosis: a systematic literature review. Semin Arthritis Rheum 2008;37:223-235.

84. Tan EM, Rodnan GP, Garcia I, Moroi Y, Fritzler MJ, Peebles C. Diversity of antinuclear antibodies in progressive systemic sclerosis: anti-centromere antibody and its relationship to CREST syndrome. Arthritis Rheum 1980;23:617-625.

85. Reveille JD, Solomon DH; American College of Rheumatol- ogy Ad Hoc Committee of Immunologic Testing Guidelines. Evidence-based guidelines for the use of immunologic tests: anticentromere, Scl-70, and nucleolar antibodies. Arthritis Rheum 2003;49:399-412.

86. Powell FC, Winkelmann RK, Venencie-Lemarchand F, Spurbeck JL, Schroeter AL. The anticentromere antibody: disease specificity and clinical significance. Mayo Clin Proc 1984;59:700-706.

87. Bernstein RM, Callender ME, Neuberger JM, Hughes GR, Williams R. Anticentromere antibody in primary biliary cirrhosis. Ann Rheum Dis 1982;41:612-614.

88. Hansen BU, Eriksson S, Lindgren S. High prevalence of autoimmune liver disease in patients with multiple nuclear dot, anticentromere, and mitotic spindle antibodies. Scand J Gastroenterol 1991;26:707-713.

89. Chan HL, Lee YS, Hong HS, Kuo TT. Anticentromere antibodies (ACA): clinical distribution and disease specificity. Clin Exp Dermatol 1994;19:298-302.

90. LeRoy EC. Sentinel signs and symptoms of systemic sclerosis. Curr Opin Rheumatol 1990;2:942-946.

91. Tashkin DP, Elashoff R, Clements PJ, et al. Cyclophosphamide versus placebo in scleroderma lung disease. N Engl J Med 2006;354:2655-2666.

92. Walker KM, Pope J; participating members of the Scleroderma Clinical Trials Consortium (SCTC); Canadian Scleroderma Research Group (CSRG). Treatment of systemic sclerosis complications: what to use when first-line treatment fails: a consensus of systemic sclerosis experts. Semin Arthritis Rheum 2012;42:42-55.

93. Dheda K, Lalloo UG, Cassim B, Mody GM. Experience with azathioprine in systemic sclerosis associated with interstitial lung disease. Clin Rheumatol 2004;23:306-309.

94. Bérezné A, Ranque B, Valeyre D, et al. Therapeutic strategy combining intravenous cyclophosphamide followed by oral azathioprine to treat worsening interstitial lung disease associated with systemic sclerosis: a retrospective multicenter open-label study. J Rheumatol 2008;35:1064-1072.

95. Galiè N, Hoeper MM, Humbert M, et al. Guidelines for the diagnosis and treatment of pulmonary hypertension: the Task Force for the Diagnosis and Treatment of Pulmonary Hypertension of the European Society of Cardiology (ESC) and the European Respiratory Society (ERS), endorsed by the International Society of Heart and Lung Transplantation (ISHLT). Eur Heart J 2009;30:2493-2537.

96. Nakanishi N. 2009 ESC/ERS Pulmonary Hypertension Guidelines and connective tissue disease. Allergol Int 2011;60:419-424.

97. Steen VD, Medsger TA Jr. Case-control study of corticosteroids and other drugs that either precipitate or protect from the development of scleroderma renal crisis. Arthritis Rheum 1998;41:1613-1619.

98. Saketkoo LA, Magnus JH, Doyle MK. The primary care physician in the early diagnosis of systemic sclerosis: the cornerstone of recognition and hope. Am J Med Sci 2014;347:54-63.

99. Caramella C, Avouac J, Sogni P, Puéchal X, Kahan A, Allanore Y. 
Association between rheumatoid arthritis and primary biliary cirrhosis. Joint Bone Spine 2007;74:279-281.

100. Iliffe GD, Naidoo S, Hunter T. Primary biliary cirrhosis associated with features of systemic lupus erythematosus. Dig Dis Sci 1982;27:274-278.

101. Sorensen HT, Thulstrup AM, Blomqvist P, Nørgaard B, Fonager K, Ekbom A. Risk of primary biliary liver cirrhosis in patients with coeliac disease: Danish and Swedish cohort data. Gut 1999;44:736-738.

102. Kingham JG, Parker DR. The association between primary biliary cirrhosis and coeliac disease: a study of relative prevalences. Gut 1998;42:120-122.

103. Bardella MT, Quatrini M, Zuin M, et al. Screening patients with celiac disease for primary biliary cirrhosis and vice versa. Am J Gastroenterol 1997;92:1524-1526.
104. Volta U, De Franceschi L, Molinaro N, et al. Frequency and significance of anti-gliadin and anti-endomysial antibodies in autoimmune hepatitis. Dig Dis Sci 1998;43:2190-2195.

105. Habior A, Lewartowska A, Orłowska J, et al. Association of coeliac disease with primary biliary cirrhosis in Poland. Eur J Gastroenterol Hepatol 2003;15:159-164.

106. Tada F, Abe M, Nunoi H, et al. Ulcerative colitis complicated with primary biliary cirrhosis. Intern Med 2011;50:2323-2327.

107. Xiao WB, Liu YL. Primary biliary cirrhosis and ulcerative colitis: a case report and review of literature. World J Gastroenterol 2003;9:878-880.

108. Muratori P, Fabbri A, Lalanne C, Lenzi M, Muratori L. Autoimmune liver disease and concomitant extrahepatic autoimmune disease. Eur J Gastroenterol Hepatol 2015;27:1175-1179. 